Corrigendum

\title{
Corrigendum to "The State-of-the-Art of Knowledge-Intensive Agriculture: A Review on Applied Sensing Systems and Data Analytics"
}

\author{
Barun Basnet $(\mathbb{D})$ and Junho Bang $(\mathbb{D}$ \\ Department of IT Applied System Engineering, Chonbuk National University, Jeollabuk-do, Republic of Korea \\ Correspondence should be addressed to Junho Bang; jhbang@jbnu.ac.kr
}

Received 28 October 2018; Accepted 30 October 2018; Published 16 December 2018

Copyright (c) 2018 Barun Basnet and Junho Bang. This is an open access article distributed under the Creative Commons Attribution License, which permits unrestricted use, distribution, and reproduction in any medium, provided the original work is properly cited.

In the article titled "The State-of-the-Art of KnowledgeIntensive Agriculture: A Review on Applied Sensing Systems and Data Analytics" [1], there was an error in the Acknowledgments, which should be corrected as follows:

"This research was supported by Basic Science Research Program through the National Research Foundation of Korea (NRF) funded by the Ministry of Education (2018R1D1A1B07048630). The authors also would like to thank Dr. R. P. Tasho for the suggestions on improving the quality of this paper."

\section{References}

[1] B. Basnet and J. Bang, "The state-of-the-art of knowledgeintensive agriculture: a review on applied sensing systems and data analytics," Journal of Sensors, vol. 2018, Article ID 3528296, 13 pages, 2018. 


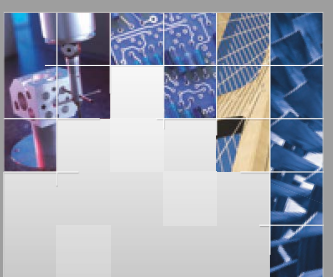

\section{Enfincering}
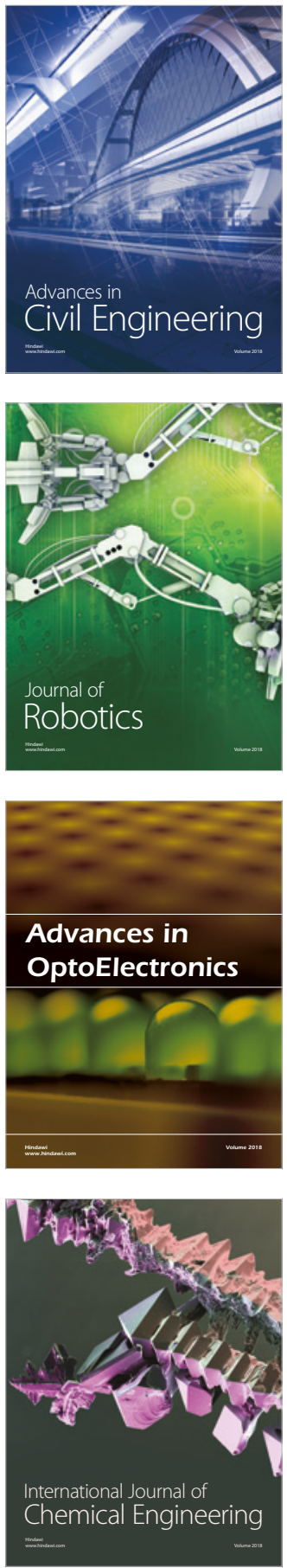

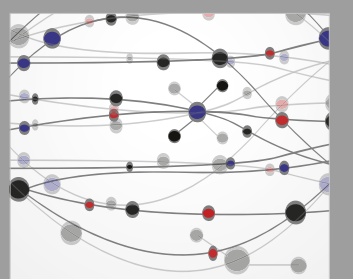

\section{Rotating \\ Machinery}

The Scientific World Journal

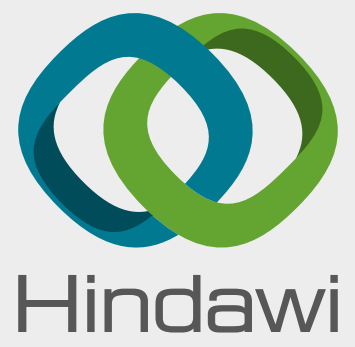

Submit your manuscripts at

www.hindawi.com
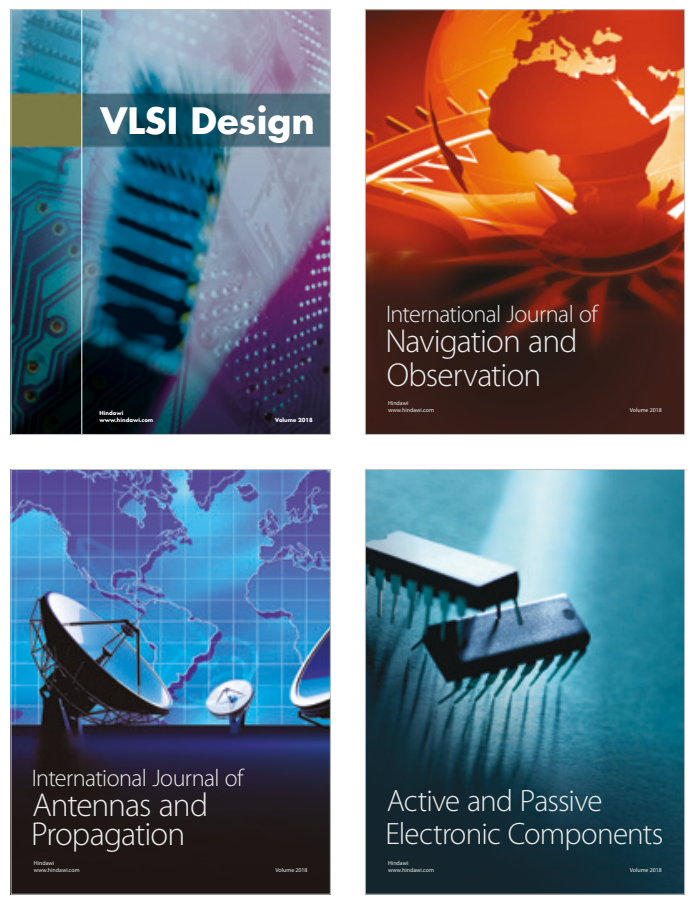
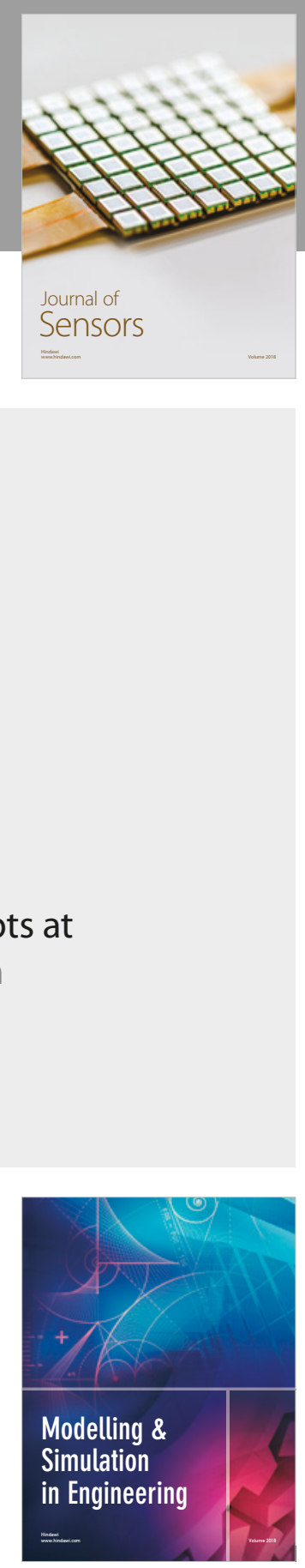

\section{Advances \\ Multimedia}
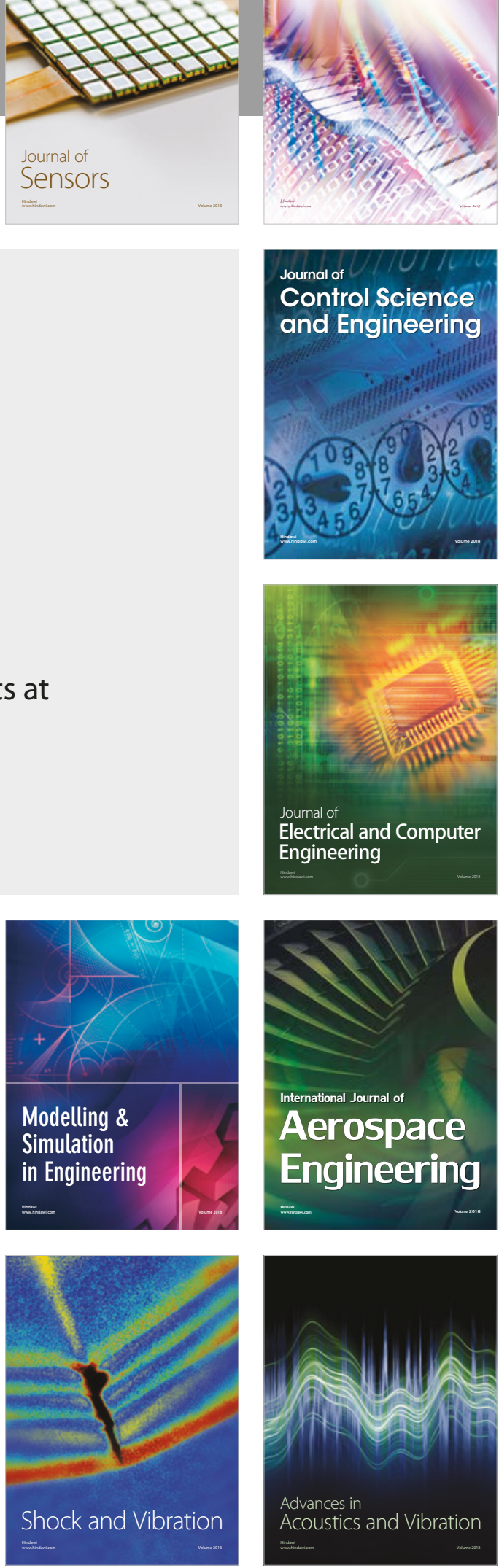